\title{
Health claims on functional foods: the Japanese regulations and an international comparison
}

\author{
Toshio Shimizu \\ Fresco Japan Ltd. Z-22-20-102, Akasaka, Minato-ku, Tokyo, Japan
}

\begin{abstract}
The Japanese scientific academic community defined 'functional food' early in the 1980s. That is, functional foods are those that have three functions. The primary function is nutrition. The secondary function is a sensory function or sensory satisfaction. The third is the tertiary function, which is physiological. The Japanese Ministry of Health, Labour, and Welfare (MHLW) set up 'Foods for Specified Health Use' (FOSHU) in 1991 as a regulatory system to approve the statements made on food labels concerning the effect of the food on the human body. Food products applying for approval by FOSHU are scientifically evaluated in terms of their effectiveness and safety by the Council of Pharmaceutical Affairs and Food Hygiene under the MHLW. The regulatory range of FOSHU was broadened in 2001 to accept the forms of capsules and tablets in addition to those of conventional foods. FOSHU increased the total to about 330 items in January 2003. The MHLW enacted a new regulatory system, 'Foods with Health Claims', in April 2001, which consists of the existing FOSHU system and the newly established 'Foods with Nutrient Function Claims' (FNFC). Under the FNFC, twelve vitamins (vitamins A, $\mathrm{B}_{1}, \mathrm{~B}_{2}, \mathrm{~B}_{6}, \mathrm{~B}_{12}, \mathrm{C}, \mathrm{E}$, $\mathrm{D}$, biotin, pantothenic acid, folic acid, and niacin) and two minerals ( $\mathrm{Ca}$ and $\mathrm{Fe}$ ) are standardized. Examples of claims regarding these substances are as follows: 'Calcium is a nutrient which is necessary to form bones and teeth'; 'Vitamin D is a nutrient which promotes calcium absorption in the gut intestine and aids in the formation of bones.' The upper and lower levels of the daily consumption of these nutrients are also determined. The labelling of functional foods should always be based on scientific evidence and be in harmony with international standards. The nutrient-function claim was adopted in the guidelines for nutrition claims by the Codex Alimentarius in 1997. The claims of the Japanese FNFC are equivalent to the nutrient function claims standardized by the Codex Alimentarius. The enhanced function claim and the disease risk-reduction claims were proposed by both the Codex Alimentarius and an Economic Union project in 1999. The structure function claim, which is similar to the enhanced function claim, was enacted by the Dietary Supplement Health and Education Act in the USA in 1994. Most of the statements of the Japanese FOSHU system are close to the category of structure/function claims in the USA or the enhanced function claims of the Codex Alimentarius.
\end{abstract}

\section{Functional food: Foods for specified health use: Foods with health claims: Foods with nutrient-function claims}

\section{Introduction}

The labelling of functional food is important for both consumers and producers. The consumers can understand the features, contents and usage of particular foods by their labelling and then choose the proper foods using the information provided by the label. With more public information available than ever before regarding the health benefits of foods, consumers' interest in health issues has become a leading factor in their purchasing decisions. The manufacturers can emphasize the characteristics of their products and promote their sale by the use of labelling or claims. Therefore, labelling should be clear and correct and avoid any misunderstanding or ambiguity. Especially, the labelling of health claims (Table 1) regarding foods should always be based on scientific evidence.

\footnotetext{
Abbreviations: DSHEA, Dietary Supplement Health and Education Act; FDA, United States Food and Drug Administration; FNFC, Foods with Nutrient Function Claims; FOSHU, Foods for Specified Health Use; FUFOSE, European Community Concerted Action on Functional Food Science; MHLW, Japanese Ministry of Health, Labour, and Welfare.

Corresponding author: Dr Toshio Shimizu, fax +81 35549 4638, email shimizut@d2.dion.ne.jp
} 
Table 1. Definitions

\begin{tabular}{|c|c|}
\hline Term & Definition \\
\hline Functional food & $\begin{array}{l}\text { Food that has physiological functions, including regulation of biorhythms, the nervous system, the immune } \\
\text { system, and bodily defence beyond nutrient functions, as defined by the Japanese ad hoc national project in } \\
1984\end{array}$ \\
\hline Health claims & $\begin{array}{l}\text { Presentation that states, suggests, or implies that a relationship exists between a food or the constituents of } \\
\text { a food and health. Health claims include nutrient-function claims, enhanced function claims, and reduction } \\
\text { of disease risk claims. This definition is the same as that included in the Proposed Draft Guidelines for Use } \\
\text { of Health and Nutrition Claims of the Codex Alimentarius in } 1999 \text { (Codex Alimentarius Committee on Food } \\
\text { Labelling } 28 \text { Session) }\end{array}$ \\
\hline Generic health claims & $\begin{array}{l}\text { Claims based on well-established, generally accepted knowledge derived from evidence in the scientific } \\
\text { literature and/or on recommendations from national or international public health bodies }\end{array}$ \\
\hline Product-specific claims & $\begin{array}{l}\text { Claims that concern certain physiological effects other than a generic health claim, which requires demon- } \\
\text { strations based on scientific evidence for individual products }\end{array}$ \\
\hline Enhanced function claims & $\begin{array}{l}\text { Claims that concern specific beneficial effects regarding the consumption of foods and their constituents in } \\
\text { the context of the total diet regarding physical or psychological functions or biological activities but that do } \\
\text { not include nutrient function claims }\end{array}$ \\
\hline Structure/function claims & $\begin{array}{l}\text { Any statements regarding the effects of dietary supplementation on the structure or function of the body, that } \\
\text { is defined by the Dietary Supplement, Health and Education Act in the USA in } 1994 \text {. These claims are gener- } \\
\text { ally similar to the enhanced function (or other) claims }\end{array}$ \\
\hline Dietary supplement & $\begin{array}{l}\text { A product intended to supplement the diet, which contains one or more of dietary ingredients such as vita- } \\
\text { mins, minerals, herbs, amino acids, etc, which is in a dosage form such as capsules, tablets, etc }\end{array}$ \\
\hline
\end{tabular}

Research on the health benefits of foods started systematically in Japan in 1984. The Ministry of Education, Science and Culture launched a national project concerning research and development on the functionalities of food. The project involved researchers interested in nutrition, pharmacology, psychology and medical science. The project defined a 'functional food' for the first time (Table 1). That is, foods have three functions. The primary is a nutritional function, which is essential for an individual to survive. The secondary is sensory function, or sensory satisfaction, such as deliciousness, flavour, and pleasing texture. The tertiary is a physiological function, such as regulation of biorhythm, the immune system, and body defence. The project was the first to define functional food as a food that has a tertiary function (Arai, 1996), and found many food components that had tertiary functions during one decade. As more studies regarding the physiological functions of foods are conducted, scientific evidence for the tertiary function of food is accumulating (Arai, 2002).

\section{The Japanese system}

\section{Foods for specified health use}

The results of research and development on the physiological function of foods prompted the Japanese Ministry of Health, Labour, and Welfare (MHLW) to establish a regulatory system regarding foods that claim health benefits, aimed at informing the public of health information concerning specific foods. 'Foods for Specified Health Use' (FOSHU) was set up by the MHLW in 1991 as the regulation system to approve statements contained on a label regarding the effects of foods on the human body.

FOSHU was enacted under the Nutrition Improvement law. This law lists five categories of 'food for special dietary uses': (1) milk powder for pregnant and lactating women; (2) formulated milk powder for infants; (3) foods for elderly individuals with difficulty in masticating or swallowing; (4) medical foods for the ill; (5) FOSHU.
Application. Those who wish to submit their products for FOSHU approval should submit the following documentation to the MHLW:

- a sample of the entire package including labels and health claims;

- documentation that demonstrates the clinical and nutritional proof of the product and/or its functional components aimed at the maintenance of health;

- documentation that demonstrates clinical and nutritional proof of the intake amount of the product and/or its functional component;

- documentation concerning the safety of the product and its functional component, including additional human studies regarding the eating experience;

- documentation concerning the stability of the product and its functional component;

- documentation of the physical and biological characteristics of the product and its functional component;

- details of methods of qualitative and quantitative analytical determination of its functional component, and the analytical results regarding the components of the product;

- a report describing the analysis of the designated nutrient constituents and the product's energy content;

- a statement of the method and equipment used in the food's production, and an explanation of the qualitycontrol system.

The above documentation could be summarized into three essential requirements for FOSHU approval. The first is effectiveness based on scientific evidence, including clinical studies. The second is the safety of the product with additional safety studies in human subjects. The last is analytical determination of the effective components.

Regarding effectiveness, the documents should be prepared on the basis of substantiation not only by human intervention studies but also by in vitro metabolism and biochemical studies and animal studies (Morinaga et al. 
2000). These data should demonstrate statistically significant differences. Basically, a human study should be conducted by using the food in question over a reasonably long-term period (for example, more than 2 or 3 months). A human study should be approved by a committee on ethics in consideration of human rights protection, in accordance with the principles of the Helsinki Declaration (adopted in 1964 and revised in 1996). The study should also be well designed, for example using an appropriate functional marker, appropriate sample size, and a sufficient number of subjects to prove statistically significant differences. All available literature regarding the related functional components, the related foods and the related functions should be reviewed.

Any new scientific evidence used to support healthrelated claims must be published by a suitably qualified journal with expert referees who can review the evidence. Generally more than two human studies are required for different targeted individuals. Human studies of some approved FOSHU are listed in Table 2.

As for safety, both in vivo and in vitro studies should be carried out in order to obtain preliminary data confirming the food's safe intake by human consumers. Even if an effective component has been consumed as food by a reasonable number of individuals during a certain period, safety data for human consumers should be required for at least three times the minimum effective dosage. The literature regarding related functional components should be reviewed. If the related literature suggests an especially undesirable or adverse health effect, the report should be included as a reference with the scientific explanation or the human study that confirms the product's safety for human consumers.

Concerning analysis, documentation of the methods for analysis of related functional components should submit the suitable and reliable methods of quantitative and qualitative analytical determination. These analytical determinations must be carried out before the clinical studies, animal studies, in vitro studies, and stability tests.

As additional documentation, the stability of related functional components should be confirmed. The effective components and other components with an undesirable or adverse health effect should be confirmed to demonstrate the specified amount through the use of suitable analytical methods. If a product is in the form of tablets or capsules, experiments should be conducted regarding its characteristics of disintegration or dissolution.

Evaluation and approval. The application including the above documentation will be received and checked at the Office of Health Policy on Newly Developed Foods of the MHLW. The office convenes two expert committees, which consist of experts on nutrition, pharmacology and medical science. The first committee, consisting of eight experts, evaluates the products with regard to metabolism and internal secretion, renal function and blood pressure. The second one, which consists of ten experts, evaluates aspects related to the gut intestine condition, the immune system and other functions. During the course of the evaluation, supplemental documentation or amendments might be requested by the office, if necessary.

After evaluation by the expert committee in charge, the office of the MHLW passes the application to the Council of Pharmaceutical Affairs and Food Hygiene, which makes a final evaluation. The Council might ask for additional documentation from the applicant, if necessary. When the Council determines the application to be appropriate after due discussion, the MHLW notifies the applicant and asks the applicant to send samples of the product with documentation regarding the analytical method of the effective component to the National Institute of Health and Nutrition, which validates the method and determines the contents of the effective component. After the validation and determination have been completed, the MHLW makes the decision to grant approval for the product under FOSHU. The applicant can label the approved health claim and authorize the FOSHU mark, which symbolizes 'jumping for health' (Fig. 1), to be placed on the product. In the application, if an effective component of the product being applied for is the same as an already-approved FOSHU product, but has a different form as a food, the procedure for evaluating the product being applied for by the committee might be shortened.

The evaluation of both the benefits and safety of functional foods should differ from those of medicines. The targets of functional foods are healthy individuals or individuals in a preliminary stage of a disease or with a borderline condition in an at-risk group. Therefore, the effectiveness of such foods for these individuals might be less distinct than that of medicine in patients with a particular condition.

FOSHU applications are accepted every 3 months (usually March, June, September and December). The minimum period required for the approval process is 6 months, which begins with receipt of the application and extends to FOSHU approval by the MHLW. However, this period does not include extra time needed for inquiries from the office of the MHLW, the committee, and the Council, and responses to the inquiries. The practical minimum period required for approval is approximately 1 year.

The applicant should validate the quality, effectiveness, and safety of the product approved by FOSHU, taking new scientific studies and post-marketing research into consideration. Competent authorities in the MHLW can inspect manufacturing plants and evaluate the effectiveness, the post-marketing research, and research on the adverse effects of FOSHU products, when necessary, by requiring related documentation. If a new study regarding adverse effects, a negative study concerning effectiveness, or if fraud or an untruthful act in the production or the specification of the product were to be found in the process of inspection, the MHLW could publish it, and request the manufacturer not to produce the product or to withdraw FOSHU approval.

Health claims on foods for specified health use. FOSHU claims are health-related functions that can have positive effects on human physiological functions, and the related 


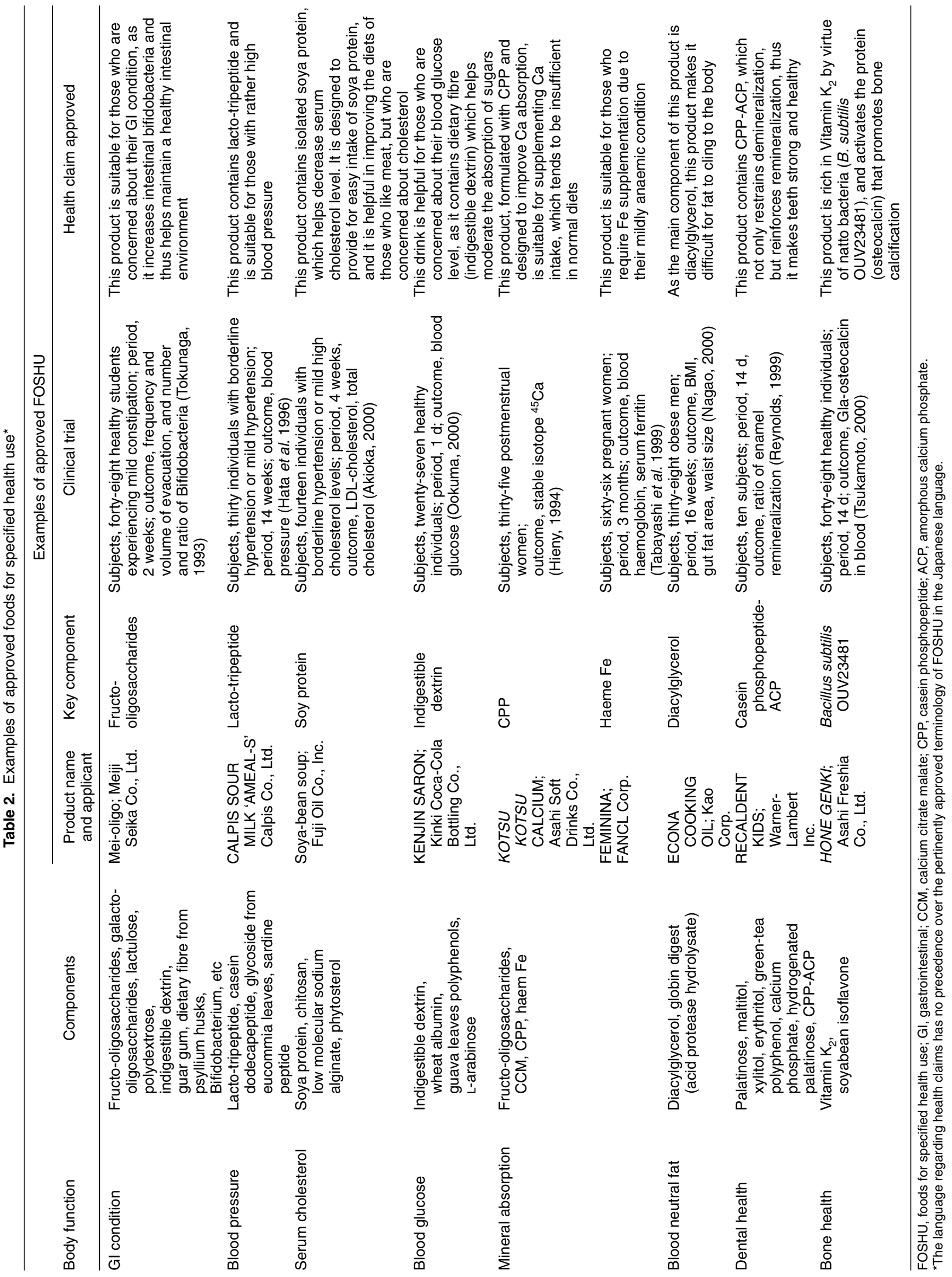




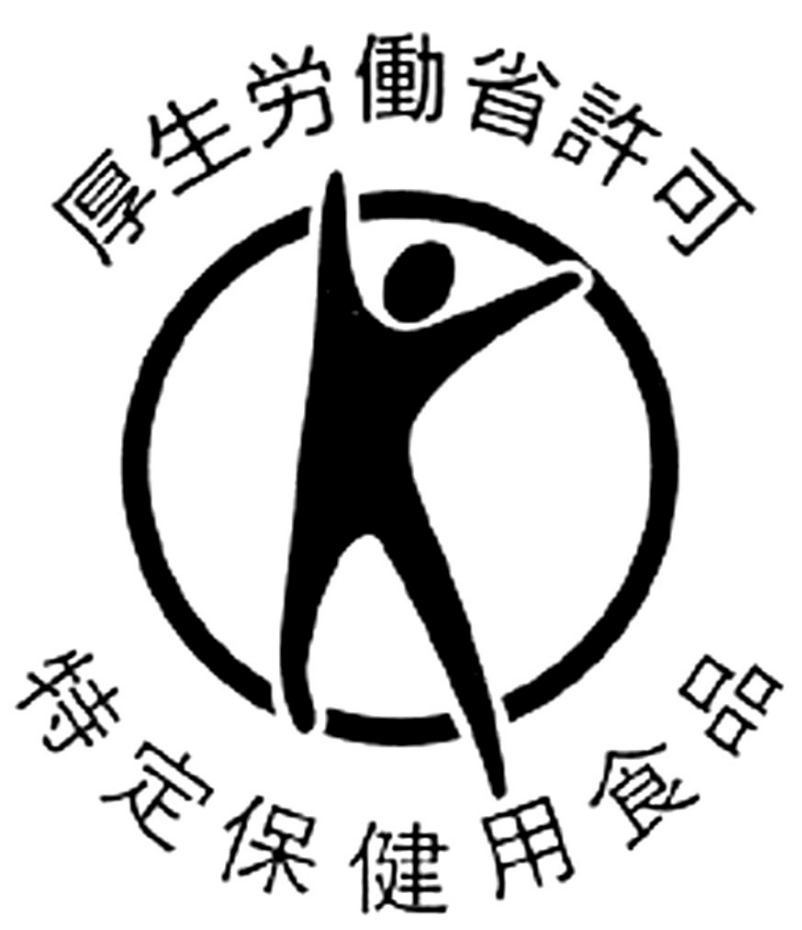

Fig. 1. Seal of approval used by Foods for Specified Health Use regulatory system in Japan.

foods are intended to be consumed for the maintenance or promotion of health or special health uses by individuals who wish to control their health conditions. The number of items approved by FOSHU has increased to approximately 330 in January 2003. FOSHU health claims must not include medical claims such as claims to 'prevent', 'cure', 'treat', or 'diagnose' human diseases. The MHLW defines the allowed health claims as follows (Shimizu et al. 2001):

- A claim to maintain or improve a functional marker which can be easily evaluated by, for example, self-diagnosis or a health check-up. A permitted claim, for example, could be: 'This product helps to maintain normal sugar levels', or 'This product promotes decomposition of body fat.' A disallowed claim would be, for example: 'This product improves hypertension.'

- A claim to maintain or improve physiological function and organ function of the human body. A permitted claim, for example, could be: 'This product enhances the absorption of calcium', or 'This product helps to improve bowel movements.' A disallowed claim would be, for example: 'This product is an effective food for enhancing fat metabolism.'

- A claim to improve physical condition subjectively and temporally, but not persistently or chronically. A permitted claim, for example, could be: 'This product is good for or helps those who feel physical fatigue.' A disallowed claim would be, for example: 'This product has anti-ageing effects.'

The health claims approved by FOSHU can be categorized into the following eight groups according to health claims (Table 2):
- Gastrointestinal condition; about half the FOSHU products claim to improve gastrointestinal condition, the effective components being carbohydrates. These can be divided into oligosaccharides (Tokunaga, 1993), dietary fibres (Yamatoya, 1995), and chitosan. Outcomes of intake are frequency and volume of evacuation, and the number and ratio of bifidobacteria. Approved products containing these components can claim that the carbohydrate helps increase intestinal bifidobacteria, thus aiding in the maintenance of good gastrointestinal condition.

- Blood pressure; lacto-tripeptide from fermented milk (Hata et al. 1996), dodeca-peptide from casein (Sekiya et al. 1992), and a group of peptides from sardine (Fujita, 2001) and soya protein could decrease blood pressure, and approved products containing these components can claim that the product is suitable for individuals with slightly elevated blood pressure. Functional markers are systolic blood pressure and diastolic blood pressure.

- Serum cholesterol; the effective components are soya protein (Akioka, 2000), chitosan (Maezaki, 1993), low-molecular sodium alginate (Asaoka, 1996), and phytosterol. Approved products containing these components can claim that the product helps individuals decrease their serum cholesterol levels. Markers are serum total cholesterol, LDL-cholesterol, and HDL-cholesterol levels.

- Blood glucose; the effective components are indigestive dextrin (Ookuma, 2000), wheat albumin, L-arabinose (Sakai, 2001), and so on. Approved products containing these components can claim that the product is helpful for those who are concerned about their blood glucose levels. Markers are blood glucose, glycohaemoglobin, fructosamine and blood insulin levels.

- Absorption of minerals; fructo-oligosaccharides, caseinphosphopeptide (Hieny, 1994), and so on could improve $\mathrm{Ca}$ absorption in the gut intestine, while haem-Fe (Tabayashi et al. 1999) has a high level of Fe bioavailability. Approved products containing these components claim that the products provide high bioavailability for human consumers and are suitable for $\mathrm{Ca}$ supplementation. Approved products containing haem-Fe from haemoglobin could claim that such products are suitable for those with mild anaemia, who need supplemental Fe.

- Blood lipids; diacylglycerol (Nagao, 2000) and globin digest (Kagawa, 1999) could decrease blood lipid levels after meals. Approved products containing these ingredients claim that they help reduce postprandial serum triacylglycerol levels. Additionally, a product containing diacylglycerol is permitted to claim that the product inhibits an increase in levels of body fat. Markers are blood lipid levels and BMI.

- Dental health; some sugar alcohols such as xylitol, maltitol, erythritol, and palatinose are low in cariogenicity, green-tea polyphenol casein is non-cariogenic, and phosphopeptide-amorphous calcium phosphate (Reynolds, 1999) is anti-cariogenic. Approved products containing these ingredients can claim that the products are low- or non-cariogenic or make teeth strong and healthy. Markers are oral $\mathrm{pH}$ and demineralization of enamel slabs in the human mouth.

- Bone health; vitamin $\mathrm{K}_{2}$ (Tsukamoto, 2000), milk basic protein (Yamamura, 2001), and soya isoflavones could 
promote bone calcification. Approved products containing them can claim that the product helps promote bone calcification or helps increase bone density to make healthy bones. Markers are bone mineral density and Gla-osteocalcin in blood.

\section{Foods with nutrient function claims}

In 1988, the MHLW organized an expert group for discussing the regulations of so-called dietary supplements. The definition of 'dietary supplement' used in the meeting is foods that are sold for the purpose of nutritional supplement or for specified health uses (Table 1). The components under consideration include vitamins, minerals, herbs, and other food elements. The MHLW enacted a new regulatory system, 'Foods with Health Claims', in April 2001 (Fig. 2; Shimizu, 2002). Foods with Health Claims consists of two categories, FOSHU and 'Foods with Nutrient Function Claims' (FNFC). Twelve vitamins (vitamins $\mathrm{A}, \mathrm{B}_{1}, \mathrm{~B}_{2}, \mathrm{~B}_{6}, \mathrm{~B}_{12}, \mathrm{C}, \mathrm{E}, \mathrm{D}$, biotin, pantothenic acid, folic acid, and niacin) and two minerals (Ca and Fe) are standardized as FNFC (Shimizu et al. 2001; Codex Alimentarius Commission, 2002).
Nutrient function claims. Nutrient/function claims (Table 3) are determined according to the recommendations of the Codex Alimentarius in 1997. These claims have been widely accepted by scientific experts, based on scientific evidence regarding existing foods or supplements internationally and are readily understood by the general public.

Upper and lower limits. An FNFC product should contain an amount of the nutrient between the designated upper and lower limits (Table 4). The lower limit was set as one-third of the recommended daily intake for Japanese and the upper limit was determined as the maximum amount of nutrient items in 'over the counter' drugs.

Future aspects of foods with nutrient function claims. The MHLW is currently discussing the standardization of new nutrient/function claims for other nutrients, such as vitamin $\mathrm{K}$, ten minerals ( $\mathrm{Mg}, \mathrm{Cu}, \mathrm{Zn}, \mathrm{Se}, \mathrm{P}, \mathrm{K}, \mathrm{I}, \mathrm{Mn}, \mathrm{Cr}$, and $\mathrm{Mo}$ ),

\begin{tabular}{|c|c|c|c|}
\hline \multirow[b]{2}{*}{$\begin{array}{l}\text { Drug } \\
\text { (including } \\
\text { quasi-drugs) }\end{array}$} & \multicolumn{2}{|c|}{ Foods with Health Claims } & \multirow[b]{2}{*}{$\begin{array}{l}\text { Other foods } \\
\text { (including part } \\
\text { of so-called } \\
\text { health food) }\end{array}$} \\
\hline & $\begin{array}{l}\text { Foods for } \\
\text { Specified Health Uses } \\
\text { (individual approval } \\
\text { system) }\end{array}$ & $\begin{array}{l}\text { Foods with } \\
\text { Nutrient Function } \\
\text { Claims } \\
\text { (standard regulation } \\
\text { system) }\end{array}$ & \\
\hline & $\begin{array}{l}\text { Nutrient contents labelling } \\
\text { Health claims labelling } \\
\text { (Nutrition claims labelling) }\end{array}$ & $\begin{array}{l}\text { Nutrient contents labelling } \\
\text { (Nutrient contents labelling) } \\
\text { Nutrition claims labelling }\end{array}$ & \\
\hline & Attention and warning labelling & & \\
\hline
\end{tabular}

Fig. 2. Classification and class name.

Table 3. Nutrient function claims and warnings labelling in Japan*

\begin{tabular}{|c|c|}
\hline Nutrient & Nutrient-Function claim \\
\hline Vitamin $\mathrm{A}$ ( or $\beta$-carotene) & $\begin{array}{l}\text { Vitamin } A \text { (or } \beta \text {-carotene) is a nutrient that helps to maintain vision in the dark. Vitamin } A \text { (or } \beta \text {-carotene) is a } \\
\text { nutrient which helps to maintain skin and mucosa health }\end{array}$ \\
\hline Vitamin D & $\begin{array}{l}\text { Vitamin } \mathrm{D} \text { is a nutrient that promotes the absorption of } \mathrm{Ca} \text { in the gut intestine and aids in the development of } \\
\text { bone }\end{array}$ \\
\hline Vitamin E & Vitamin $E$ is a nutrient that helps to protect fat in the body from being oxidized and to maintain cell health \\
\hline Vitamin $\mathrm{B}_{1}$ & $\begin{array}{l}\text { Vitamin } B_{1} \text { is a nutrient that helps to produce energy from carbohydrates and to maintain skin and mucosa } \\
\text { health }\end{array}$ \\
\hline Vitamin $\mathrm{B}_{2}$ & Vitamin $B_{2}$ is a nutrient that helps to maintain skin and mucosa health \\
\hline Vitamin $\mathrm{B}_{6}^{2}$ & Vitamin $B_{6}$ is a nutrient that helps to produce energy from protein and to maintain skin and mucosa health \\
\hline Niacin & Niacin is a nutrient that helps to maintain skin and mucosa health \\
\hline Biotin & Biotin is a nutrient that helps to maintain skin and mucosa health \\
\hline Pantothenic acid & Pantothenic acid is a nutrient that helps to maintain skin and mucosa health \\
\hline Folic acid & $\begin{array}{l}\text { Folic acid is a nutrient that aids in erythrocyte formation. Folic acid is a nutrient that also contributes to the } \\
\text { normal growth of the fetus }\end{array}$ \\
\hline Vitamin $\mathrm{B}_{12}$ & Vitamin $B_{12}$ is a nutrient that aids in erythrocyte formation \\
\hline Vitamin D & $\begin{array}{l}\text { Vitamin } \mathrm{D} \text { is a nutrient that promotes the absorption of } \mathrm{Ca} \text { in the gut intestine and aids in the development of } \\
\text { bone }\end{array}$ \\
\hline Vitamin C & Vitamin $C$ is a nutrient that helps to maintain skin and mucosa health and has an antioxidizing effect \\
\hline & is a nutrient necessary for the development of bone and teeth \\
\hline $\mathrm{Fe}$ & $\mathrm{Fe}$ is a nutrient necessary in erythrocyte formation \\
\hline
\end{tabular}

* Attention and warning labelling is as follows: for every nutrient, 'Excess intake of this product neither cures disease nor promotes health. Ingest no more than the optimum amount.'; for vitamin A, 'Women who are pregnant or expect to become pregnant should avoid excess intake.'; for folic acid, 'Folic acid is a nutrient contributing to normal growth of the fetus but does not improve the growth of the fetus with excess intake.' 
Table 4. The upper limit and the lower limit of nutrients in foods with nutrient-function claims

\begin{tabular}{lcc}
\hline & Upper limit & Lower limit \\
\hline Vitamin A (retinol) $(\mathrm{IU})$ & 2000 & 600 \\
Vitamin $D(\mathrm{IU})$ & 200 & 35 \\
Vitamin $E(\mathrm{mg})$ & 150 & 3 \\
Vitamin $B_{1}(\mathrm{mg})$ & 25 & $0 \cdot 3$ \\
Vitamin $B_{2}(\mathrm{mg})$ & 12 & $0 \cdot 4$ \\
Niacin $(\mathrm{mg})$ & 15 & 5 \\
Vitamin $B_{6}(\mathrm{mg})$ & 10 & $0 \cdot 5$ \\
Folic acid $(\mu \mathrm{g})$ & 200 & 70 \\
Vitamin $B_{12}(\mu \mathrm{g})$ & 60 & $0 \cdot 8$ \\
Biotin $(\mu \mathrm{g})$ & 500 & 10 \\
Pantothenic acid $(\mathrm{mg})$ & 30 & 2 \\
Vitamin $C(\mathrm{mg})$ & 1000 & 35 \\
Ca $(\mathrm{mg})$ & 600 & 250 \\
Fe $(\mathrm{mg})$ & 10 & 4 \\
\hline
\end{tabular}

and unsaturated fatty acids ( $\alpha$-linoleic acid, docosahexaenoic acid and eicosapentaenoic acid), which will be enacted in the middle of 2003.

\section{The overseas situation}

\section{Codex Alimentarius}

The Codex Alimentarius is of great importance for world trade and, although advisory, has defined three types of health claims: nutrient function claims; enhanced function claims (Table 1); reduction of disease risk. Guidelines for the use of nutritional claims by the Codex Committee on Food Labeling (Codex Alimentarius Commission, 1997) proposed that "nutrient function claim is the claim that describes the physiological role of the nutrient in growth, development, and the normal function of the body'. The nutrients include three major nutrients, ten vitamins, and six minerals.

Another Codex Alimentarius Committee (Codex Alimentarius Commission, 2000) proposed that 'enhanced function claim concerns specific beneficial effects of the consumption of foods and their constituents in the context of the total diet on physical or psychological functions or biological activities but does not include nutrient function claim. Such claims relate to a positive contribution to health or to improvement of a function or to modifying or preserving health.' 'Disease Risk Reduction Claim' relates to the consumption of a food or food constituent, in the content of the total diet, to the reduced risk of developing a disease or a health-related condition. Risk reduction means significantly altering a major risk factor(s) for a disease or a health-related condition. Diseases have multiple factors and altering one of these risk factors may or may not have a beneficial effect. The presentation of Risk Reduction Claims must ensure, for example, by use of appropriate language and reference to other risk factors, that consumers do not interpret them as prevention claims.'

\section{North America}

United States of America. The Nutrition Labeling and Education Act in the USA was established in 1990 and allowed a claim that describes a relationship between a food substance and a disease or health-related condition, which is generally similar in concept to the reduction of risk of disease of Codex Alimentarius 2000, authorized by the United States Food and Drug Administration (FDA) which reviewed the scientific literature. The US health claims pertaining to substance-disease relationships, for example, 'diets high in calcium may reduce the risk of osteoporosis', may be made on the labels of foods and dietary supplements. The 1997 FDA Modernization Act allowed claims concerning the relationship between foods or their components and the risk reduction of specific diseases based on an 'authoritative statement' of the scientific body of the US government or the National Academy of Sciences instead of an authorization of the FDA.

The structure/function claim (Table 1), which was defined by the Dietary Supplement Health and Education Act (DSHEA) in the USA, is a statement that describes the role of a nutrient or dietary ingredient intended to affect bodily structure or function in man or that characterizes the mechanism by which a nutrient or dietary ingredient acts to maintain such a structure/function relationship, for example, 'calcium builds strong bones' (United States Food and Drug Administration, 2000a,b). Under the DSHEA, dietary supplement manufacturers can sell their product with any structure-function claims by the notification of the claim they make. The manufacturer is responsible for ensuring the accuracy and truthfulness of these claims; their files including substantiation of any structure/function claims require neither to be checked for accuracy by any independent experts nor to be open to the public (United States Food and Drug Administration, 2001).

Canada. Health Canada has initiated a process to review the science supporting the US health claims in 1999, and published the consultation document on generic health claims (Health Canada, 2002) that proposed elements and conditions for the use of the following five generic health claims (Table 1): $\mathrm{Na}$ and its effect on hypertension; $\mathrm{Ca}$ and osteoporosis, saturated and trans fat and cholesterol and CHD, fruits and vegetables and cancer; sugar alcohols and dental caries.

The document commented that diseases had multiple risk factors and that altering one of these risk factors may or may not have a beneficial effect. The presentation of risk-reduction claims must ensure, for example, by use of appropriate language and reference to other risk factors, that consumers do not interpret them as prevention claims.

\section{Europe}

European Union. At present there are no Europe-wide regulations in place to regulate health claims; this includes not only European Union directives but also domestic legislations of the member states. The scientific concepts of the European Community Concerted Action on Functional Food Science (FUFOSE), which has been coordinated by the International Life Science Institute Europe, defined the same nutrient function claims as that of the Codex Alimentarius 
(Diplock et al. 1999). An example of such a statement is: 'Calcium aids in the development of strong bones and teeth.' The FUFOSE proposed in 1998 enhanced function claims and reduction of disease risk claims (Diplock et al. 1999), which were before the enhanced function claims and reduced risk of disease claims proposed by the Codex Alimentarius Commission in 1999 (Codex Alimentarius Commission, 2002).

The European Union Process for the Assessment of Scientific Support for Claims on Foods project was established in 2001 to provide industry, academics, consumer groups, and regulators with the means to evaluate the scientific basis for health claims (Verschuren, 2002).

United Kingdom. The Joint Health Claims Initiative (UK Joint Health Claims Initiative, 1998), which was established voluntarily by consumer organizations, enforcement authorities, and industry trade associations in the UK in 1997 to establish a code of practice for health claims regarding food, proposed the following two types of health related claims.

First, generic health claims are based on well-established, generally accepted knowledge from evidence in the scientific literature and/or on recommendations from national or international public health bodies.

Second, innovative health claims are claims other than generic health claims based on scientific evidence applied to existing or new foods and substantiated in accordance with the Code.

In the case of the generic health claims, which are standardized by an expert authority, no specific substantiation is required individually. Concerning the reduction of disease risk claims, the Code expressed that: 'If the product is proven to provide a health benefit which can reduce the risk of disease, then it is acceptable to mention the part of the body which may benefit from the reduced risk of disease as long as the disease itself is not stated or implied.'

Though the Code does not seek to replace food legislation, and does not compete with the current regulatory systems, the Code applies to any claim, made in advertising, marketing promotion, or product labelling that a food provides a specific health benefit to consumers. Under the Code Administration Body, an expert committee was established to advise on the establishment of a list of generic claims, and consider the scientific evidence submitted by companies wishing to make an innovative health claim (UK Joint Health Claims Initiative, 2002).

Sweden. The Swedish Code standardizes generic claims related to eight well-established diet and health relationships (Swedish Nutrition Foundation, 1996). These eight connections are: (1) obesity-energy content; (2) cholesterol levels in the blood-fat quality or some soluble dietary fibre; (3) blood pressure-salt $(\mathrm{NaCl})$; (4) arteriosclerosis (blood cholesterol level and blood pressure) $-n-3$ fatty acids in fish products; (5) constipation-dietary fibres; (6) osteoporosis-Ca; (7) caries-absence of sugars and other easily fermented carbohydrates; (8) Fe-deficiency anaemia-Fe.
The Swedish Code of Practice (Asp \& Trossing, 2001), 'Health Claims in the Labelling and Marketing of Food Products', was later extended to product-specific physiological claims (Table 1) in 2001. For product-specific physiological claims labelling, independent experts evaluate the scientific documents substantiating the effects of the food product presenting a product-specific physiological claim. Product-specific physiological claims must be based on studies that are scientifically sound and unobjectionable, showing the effects that are claimed.

The Netherlands. The Code of Practice in the Netherlands (Code of Practice Assessing the Scientific Evidence for Health Benefits Stated in Health Claims on Food and Drink Products) was drawn up voluntarily in conjunction with the Netherlands Nutrition Centre (Voedingscentrum), corporate organizations, consumer organizations, advisory and extension services, scientific institutes, and the Dutch government in 1998 (Voedingscentrum, 1998). The scientific evidence regarding health benefits is assessed by an independent panel, which was established in the Netherlands Nutrition Centre under the code, at the request of the party using or intending to use the health claim for the marketing of a product. There are two approved products, whose claims relate to decreasing blood cholesterol levels.

\section{Asia and Pacific countries}

China. The Ministry of Health established the regulation for the Control of Health Food in 1996, in which health food is defined as a food that has the function of regulating the human body but is not used for therapeutic purposes. The effects of health food must be demonstrated by necessary animal and/or human functional tests that demonstrate that the product has a definite and stable health function. Food products that claim health functions shall be reviewed and approved by the Ministry of Health (Zhao, 1999; S Chen, unpublished results). Human intervention studies are not essential in this evaluation system, which reflects the concept of traditional Chinese medicine in which food and drugs are considered to be from the same source. Traditional ingredients account for $70 \%$ of categories of health foods in China (S Chen, unpublished results). The examples of products and the health claims on approved health foods are as follows (S Chen, unpublished results): regulating blood lipids (monoacylglycerol, tea polyphenol, and pollen); regulating immune function (royal jelly, soyabean oil, shark powder, spirulina, and pollen); delaying the ageing process (wolfberry and honey); controlling obesity (soyabean oil, orange peel, and shark fin); reducing blood sugar (milk, glycine, glutamic acid, and Cr salt); improving memory (Chinese yam, poria, pig-brain extract and phospholipids); improving stamina (turtle, honey, and jujubee). 
Australia and New Zealand. The Australia New Zealand Food Authority, which was established to protect the health and safety of the populace in Australia and New Zealand by maintaining a safe food supply, is conducting a pilot scheme to establish a management framework for health claims using one health claim. Food labels may claim to improve diets and reduce death and illness rates. The health claim to be trialled in the pilot scheme describes the link between adequate maternal dietary folate intake and reducing the risk of neural-tube defects in newborn infants (Food Standards Australia New Zealand, 2002). Health claims are messages that make a direct link between eating a food or a nutrient in a food and reduced risk of disease. An example of a health claim is, on the front of a pack: 'A woman's diet rich in folate may help prevent spina bifida in her baby.'

Currently the Food Standards Code prohibits the general use of health claims on food labels. The existing prohibition is monitored and enforced by the New Zealand and State and Territory health agencies. The Australia New Zealand Food Authority has amended the Food Standards Code to allow for the first time the use of folate and neuraltube-defect health claims on foods.

Ultimately, if the pilot scheme is successful, a more general health claims system might be introduced to widen the opportunities for specific product promotion (Food Standards Australia New Zealand, 2002).

\section{International comparison}

\section{General concept}

Initially essential is scientific substantiation of the effectiveness and adverse effects including human studies. The draft guidelines for use of Nutrition and Health Claims in the Codex Alimentarius (Codex Alimentarius Commission, 2002) proposed that 'health claims must be based on current relevant scientific substantiation and the level of proof must be sufficient to substantiate the type of claimed effect as recognized by generally accepted scientific review of the data, and the scientific substantiation should be reviewed as new knowledge becomes available'. In the FOSHU approval system an applicant is required to substantiate the health claim by the statistical analysis of the clinical studies, animal tests, and in vitro metabolism and biochemical studies, as described earlier (p. 243). These requirements are generally similar to the Code of Practice on Health Claims on Foods established in the UK in 1998 (UK Joint Health Claims Initiative, 1996) and The Code of Practice Assessing the Scientific Evidence for Health Benefits stated in Health Claims on Food and Drink Products in the Netherlands (Voedingscentrum, 1998).

Second is totality of evidence. FOSHU documentation requires that not only the experimental data but also all the available scientific evidence including published scientific literature should be reviewed systematically. This is a generally similar concept to the totality of evidence in the Code in the UK (UK Joint Health Claims Initiative, 1998), which stated: "Any innovative health claim must be supported by documentation of the scientific evidence demonstrating the specific physiological effect which is claimed. The documentation must provide key evidence to substantiate the innovative health claim and reflect the totality of the evidence available including relevant associated research. There must be systematic evaluation of all the data, and the conclusion on which the innovative health claim is based should reflect the extent and quality of the data.' As for the way of confirming the benefit and safety of a product in a human study, any existence of undesirable or adverse effects should be additionally examined.

Consumers can be confident in the truthfulness of the information they find in claims when a third party has assessed the scientific substantiation behind the claim before the product enters the market. The White Paper of the European Union (Commission of the European Communities, 2000) declared: 'Consumers have the right to expect information on food quality and constituents that is helpful and clearly presented, so that informed choices can be made.' Confirmation of the scientific substantiation of a product's efficacy and any adverse effects and a view of the totality of evidence can allow consumers to make an 'informed choice'. Informed choice is also the general concept for FOSHU. The notification of the MHLW declares that consumers should have enough information on the health benefits of products to permit them to choose the products by themselves. Claims and labelling are the most important ways to inform consumers. The results of the clinical studies as well as animal studies for FOSHU application should be published in a journal that is reviewed by expert referees. Health-related claims cannot help consumers make 'informed choices' until they have been substantiated scientifically, reflecting the totality of the evidence.

\section{Health claims}

Health claims can be classified into the following three major categories, as described previously (p. 247).

Nutrient function claims. The scientific concepts of the FUFOSE project (Diplock et al. 1999) defined the same claims as that of the Codex Alimentarius. An example of such a statement is: 'Calcium aids in the development of strong bones and teeth.'

Enhanced function claims, or structurelfunction claims. Enhanced function claims were proposed by the FUFOSE (Diplock et al. 1999) and the Codex Alimentarius in 1999 (Codex Alimentarius Commission, 2002) and structure/function claims were defined in the DSHEA. The difference between them is that dietary supplements include nutrients but the enhanced function claim does not include nutrient function claims. The DSHEA in the USA enhanced the statement on structure and function of the human body in regard to vitamins, minerals, and herbs. Nutrients were not included in the enhanced function claim proposed by the Codex Alimentarius in 1999. 
Disease risk reduction claims. The Codex Alimentarius (Codex Alimentarius Commission, 2002) proposed that disease risk reduction claims relate the consumption of a food or food constituent, in the content of the total diet, to the reduced risk of developing a disease or a health-related condition. The Code in the UK (UK Joint Health Claims Initiative, 1998) stated that this is acceptable as long as the disease itself is not stated or implied. The Nutrition Labeling and Education Act in the USA permitted this kind of disease risk reduction claim in 1990; for example, 'Especially for teens and young adult women, adequate calcium in a healthful diet may reduce the risk of osteoporosis later in life.'

Most of the statements of the Japanese FOSHU are generally similar to the category of the enhanced function claims of the Codex Alimentarius. Although their statements are allowed to mention improvement of a preliminary stage of a disease or a borderline condition of an at-risk group due to an imbalanced nutrient state, a statement which relates to a specific disease or to disease in general terms is not acceptable. Further consideration is necessary in order to approve the claims allowed by FOSHU in relation to specific diseases in order to harmonize the global standard in future.

In the expanded application of content labelling, the reduction of the risk of diseases is a matter of considerable controversy throughout the world. The labelling statement regarding the reduction of disease risk has been discussed in regard to differentiating it from the 'prevention of diseases', which is classified as a medical claim.

\section{Regulatory system}

At present, systems for regulating the health claims of foods could be classified into the following three types: the standard regulation system; the notification system; the individual approval system.

The standard regulation system. In the case of the generic health claims, which could be standardized by expert authorities, no specific substantiation is required because individually a generic claim is based on well-established and generally accepted knowledge based on evidence.

The notification system. Under the DSHEA in the USA, dietary supplement manufacturers can sell their product with any structure/function claims by notification of these claims to the FDA, which are not approved by the FDA (United States Food and Drug Administration, 2001).

The individual approval system. Innovative health claims other than generic health claims should be evaluated by a third party. Claims sanctioned by FOSHU belong to innovative health claims rather than to generic health claims. Thus the Japanese MHLH is based on this type of evaluation system.
Definitions and classifications of health claims have been discussed in the Codex Alimentarius and other international committees many times, yet discussion has seldom included the regulatory system regarding the health claims. From a practical point of view, the regulatory system is important as well as definitions and classifications of health claims.

A notification system for innovative structure-function claims would be appropriate only in countries where manufacturers have the ability and responsibility to scientifically substantiate both the effectiveness and the safety of their products in consideration of the totality of the evidence. But it is difficult for a manufacturer to scientifically substantiate the effectiveness and safety of their product independently because any uniform methodology of scientific substantiation for the support of health claims has not yet been determined and is only now under discussion internationally. Consumers usually assume that the health claims of a product have been substantiated and checked for accuracy by independent experts before the product enters the market and that such claims on products will be controlled by enforcement authorities.

Health claims can be classified (Table 5) in comparison with international discussion. Most nutrient function claims proposed by the Codex Alimentarius could be generic claims. Some nutrient function claims such as those regarding nutrients with high bioavailability might belong to the category of innovative claims. Most enhanced function claims could be innovative claims for the first step of the product's development. These innovative claims should be evaluated and approved by an authority such as the FOSHU system, and not in the way of the notification system of the DSHEA in the USA. Generic claims such as nutrient function claims based on well-established, generally accepted knowledge based on sound evidence could be standardized by an expert authority without the need for specific substantiation regarding an individual product.

\section{Conclusion}

The Japanese scientific community began to substantiate scientific evidence regarding health-related effects of foods on the human body in the early 1980s and defined foods with such effects as 'functional food'. In 1991, the MHLW set up FOSHU as a regulatory system to approve the statements included on the labels of functional foods.

For FOSHU approval, not only the experimental data but also all the available scientific evidence including published scientific literature must be reviewed systematically. This is a concept similar to the scientific substantiation and the totality of evidence included in the Code of Practice for Health Claims on Foods in the UK established in 1999. Such substantiation should be based on experimental studies in human subjects as well as in animals and in vitro. The FOSHU guideline recommends a reasonably long-term clinical test whose condition is based on the results of animal testing and which should show the statistically significant differences in relation to a placebo. It also requires that the results of the clinical studies be published in a refereed journal.

The labelling of health-related foods should be based on scientific evidence always in harmony with global international standards. The nutrient function claim was included 
Table 5. Classification of foods for specified health use and foods with nutrient-function claims in comparison with the Codex Alimentarius

\begin{tabular}{|c|c|c|c|}
\hline & Nutrient function claim & $\begin{array}{l}\text { Claims of enhanced function } \\
\text { (structure/function) }\end{array}$ & $\begin{array}{l}\text { Claims of the reduction of } \\
\text { disease risk }\end{array}$ \\
\hline Japan & $\begin{array}{l}\text { FNFC (generic claims); standard } \\
\text { regulation }\end{array}$ & $\begin{array}{l}\text { FOSHU (innovative claims); individual } \\
\text { evaluation }\end{array}$ & Non-existent \\
\hline USA & & DSHEA 1994; notification system & $\begin{array}{l}\text { NLEA } 1990 \text { (generic claim); standard } \\
\text { regulatory system }\end{array}$ \\
\hline UK (voluntary code) & Code 1998 & $\begin{array}{l}\text { Code } 1998 \text { (proposal); individual } \\
\text { evaluation system }\end{array}$ & $\begin{array}{l}\text { Code } 2002 \text { (proposed); six generic } \\
\text { claims in } 2002\end{array}$ \\
\hline $\begin{array}{l}\text { Sweden (voluntary } \\
\text { code) }\end{array}$ & & $\begin{array}{l}\text { Code } 2001 \text { (proposal); individual } \\
\text { evaluation system }\end{array}$ & Code 1996; eight generic categories \\
\hline $\begin{array}{l}\text { The Netherlands } \\
\text { (voluntary code) }\end{array}$ & & $\begin{array}{l}\text { NL Code 1998; individual evaluation } \\
\text { system, two approved products }\end{array}$ & \\
\hline
\end{tabular}

in the Codex Alimentarius guidelines in 1997. Newly established claims of the FNFC in Japan are equivalent to the Codex Alimentarius nutrient function claims. Most statements of the Japanese FOSHU are generally similar to the category of the enhanced function claims proposed by the Codex Alimentarius and the European Union project or by the structure/function claims in the USA.

Following the establishment of the Nutrition Labeling and Education Act and the DSHEA in the USA and the Consensus Documents of the European Union project, federal regulation clarified that structure/function claims in the USA and many European countries are established based on their own standards. Japan started the research and development regarding the issue of health food regulation 20 years ago and established a new regulatory system for the food function claims of both product-specific claims (FOSHU) and generic claims (FNFC) in 2001. It is desirable that the national governments and international consumer and industrial organizations use this opportunity to cooperate with the Codex Alimentarius in an effort to establish international standards not only regarding healthrelated claims made by food manufacturers but also in developing a regulatory system for governing the promotion of research, production, and marketing of foods that will support the quality of life for individuals in the coming senior society.

\section{References}

Akioka H (2000) Effect on serum lipid of persons with mild high cholesterol levels. Journal of Nutritional Food 3, 37-46.

Arai S (1996) Studies on functional foods in Japan. Bioscience, Biotechnology and Biochemistry 60, 9-15.

Arai S (2002) Global view on functional foods: Asian perspectives. British Journal of Nutrition 88, Suppl. 2, S139-S143.

Asaoka T (1996) Effect of low molecular sodium alginate on serum cholesterol of healthy males. Nutrition - Evaluation and Therapy 13, 454-459.

Asp NG \& Trossing M (2001) The Swedish code on health-related claims in action - extended to product-specific physiological claims. Scandinavian Journal of Nutrition 45, 189-192.
Codex Alimentarius Commission (1997) Codex Guidelines for Use of Nutrition Claims, CAC/GL 23-1997. http://www.codexalimentarius.net

Codex Alimentarius Commission (2002) Proposed Draft Recommendations for the Use of Nutrient Health Claims. http://www.codexalimentarius.net

Codex Alimentarius Commission (2000) Proposed draft recommendations for the use of health claims, Comments from Japan, CX/FL00/9-CRD·33. http://www.codexalimentarius.net

Commission of the European Communities (2000) White Paper on Food Safety, Com (1999) 719 final of 12 January 2000. Brussels, Belgium. http://europa.eu.int/comm/dgs/health_ consumer/ library/pub/pub06_en.pdf

Diplock AT, Aggett PJ, Ashwell M, Bornet F, Fern EB \& Roberfroid MB (1999) Scientific concepts of functional food science in Europe: consensus document. British Journal of Nutrition 81, Suppl. 1, S1-S27.

Food Standards Australia New Zealand (2002) Media Releases \& Publications. http://www.foodstandards.gov.au/mediarelease publications/publications/index.cfm

Fujita H (2001) Human study of sardine peptides on blood pressure. Nutrition Research 21, 1149.

Hata Y, Yamamoto M, Ohni M, Nakajima K, Nakamura Y \& Takano T (1996) A placebo-controlled study of sour milk on blood pressure in hypertensive subjects. American Journal of Clinical Nutrition 64, 767-771.

Health Canada (2002) Consultation Document on Generic Health Claims. http://www.hc-sc.gc.ca/food-aliment/ns-sc/ne-en/ health_claims-allegations_sante/e_consultation_doc_gen.html

Hieny RP (1994) Effect of casein phospho-peptide on calcium absorption of postmenstrual women. Journal of Japan Bone Metabolism Association 12, 1-4.

Kagawa K (1999) Effect of globin digest on blood lipids. Japanese Journal of Nutrition and Food 52, 71-77.

Maezaki Y (1993) Improvement of serum cholesterol by chitosan. Bioscience, Biotechnology and Biochemistry 57, 1439-1444.

Morinaga Y, Shimizu T, Sueki K \& Hirahara T (2000) Health Claim on Functional Foods. Japan: International Life Scientific of Japan.

Nagao T (2000) Effect of diacylglycerol on body fat metabolism. Journal of Nutrition 130, 492.

Ookuma T (2000) Effects of indigestible dextrin on blood sugar. Journal of Nutritional Food 3, 19-27. 
Reynolds EC (1999) Advances in Enamel Remineralization: Casein Phosphopeptide-amorphous Calcium Phosphate. Journal of Clinical Dentistry 10, 86-88.

Sakai (2001) Improvement of blood sugar of healthy persons by L-alabinose. Journal of Nutritional Food 4, 1-4.

Sekiya S, Kobayashi Y \& Kita E (1992) Effect of hydrolyzed casein on hypertension and its adverse effect. Japanese Journal of Nutrition and Foods 45, 513-517.

Shimizu T (2002) Newly established regulation in Japan: Foods with health claims. Asia Pacific Journal of Clinical Nutrition 11, S94-S96.

Shimizu T, Morinaga Y, Tokunaga T, Seki S, Sueki K \& Hirahara T (2001) Functional Foods Science in Japan, pp. 2-13, Japan: International Life Scientific of Japan.

Swedish Nutrition Foundation (1996) Health Claims in the Labeling and Marketing of Food Products (Revised Programme): The Food Industry's Rules (Self-Regulatory Programme). Lund, Sweden: Swedish Nutrition Foundation.

Tabayashi M, Matsuda S, Shimizu T \& Huruya H (1999) Effect of enzyme-hydrolyzed heme-iron on iron deficient anemia. Japanese Journal of Clinical Nutrition 21, 48-54.

Tokunaga T (1993) Effects of furacto-oligosaccharide on bacteria flora and movement of large intestine. Bifidus 6, 143-150.

Tsukamoto T (2000) Effect of Vitamin $\mathrm{K}_{2}$ by virtue of natto bacteria on osteocalcin. Journal of Health Science 46, 317-321.

UK Joint Health Claims Initiative (1998) Code of Practice on Health Claims on Foods. Leatherhead, UK: Joint Health Claims Initiative.
UK Joint Health Claims Initiative (2002) Code of practice on health claims on foods. Executive summary. http://www.jhci. org.uk/

United States Food and Drug Administration (2000a) Regulation on Statements Made for Dietary Supplements Concerning the Effect of the Product on the Structure or Function of the Body. Federal Register 65, 999-1050.

United States Food and Drug Administration (2000b) FDA Finalizes Rules for Claims on Dietary Supplements. Talk Paper T00-1.

United States Food and Drug Administration (2001) Claims that can be made for conventional foods and dietary supplements. http://www.cfsan.fda.gov/ dms/hclaims.html

Voedingscentrum (1998) Code of Practice Assessing the Scientific Evidence for Health Benefits Stated in Health Claims on Food and Drink Products. The Hague, The Netherlands: Voedingscentrum.

Verschuren PM (2002) Functional foods: scientific and global perspectives. British Journal of Nutrition 88, Suppl. 2, S125-S130.

Yamamura Y (2001) Effects of milk basic protein on bone mineral density and bone absorption maker. Bioscience, Biotechnology and Biochemistry 66, 702-707.

Yamatoya K (1995) Effects of hydrolyzed guar gum on frequency and characteristics of evacuation. Journal of Japanese Society of Nutrition and Food Science 46, 199-203.

Zhao YH (1999) Practical Procedure of Regulatory Control of Functional Food in China. Monthly Food Chemicals 10, 92-95. 